\title{
Teaching Design for Safety Through Real Work Incidents
}

\author{
Jean Brousseau, Professor of Engineering \\ Jean_Brousseau@uqar.qc.ca \\ Abderrazak ElOuafi, Professor of Engineering, UQAR \\ Abderrazak_ElOuafi@uqar.qc.ca \\ Université du Québec à Rimouski \\ Département de mathématiques, d'informatique et de génie
}

\begin{abstract}
Good design means at least safe design. There is no doubt that engineering students have to develop the ability to design for safety in order to satisfy the expectations of the profession and of employers. According to the Canadian Engineering Accreditation Board, an appropriate exposure to safety and health must be part of any engineering curriculum.

Design for safety principles can be taught in project-based courses. Those courses provide realworld contexts for the development of design for safety skills. Design minima established in standards, regulations, and handbooks can easily be integrated throughout the curriculum in engineering science courses. In association with safety, engineering science courses may go beyond the application of standards and guidelines and prepare the student to become a better designer.

The Case Study approach is a very interesting pedagogical tool for engineering education and can be introduced in most engineering courses. When based on real work incidents and investigation reports, case studies become a perfect instrument to expose students to safety as professional engineers should apply it. To illustrate the idea, this paper presents an example of a case study based on an incident that occurred with a scissor lift. This particular case was introduced in a machine design course and helped students to link safety concepts with machine design contents.
\end{abstract}

\section{Introduction}

\subsection{Context}

Design engineers face increasing pressure to improve the level of safety in their designs. They are more and more accountable for meeting their safety responsibilities. Such pressure comes from employers, professional corporations (code of ethics, engineers act), the Workmen's Compensation Health and Safety Boards and more widely, from society itself. It is easy to understand because, in the Province of Quebec alone, machines are responsible for injuries to as many as 13,500 workers. Also, close to 24,000 young workers under the age of 24 are injured and one of them dies each month. Engineers are key persons and their role in reducing the number of victims of accidents is of paramount importance. Design engineers always have a second chance to go over their designs once again, but operators, maintenance workers and product users in general do not have the same opportunity.

As proposed by the CEAB [1], design is defined as a creative, interactive and often open-ended process subject to constraints, which may be governed to varying degrees by standards or legislations depending upon its discipline. Design applies to a variety of outcomes such as industrial, commercial and consumer products for human use, facilities, hardware, equipment, tooling, work methods and procedures, material selection and maintenance requirements. Of course when designing, safety is one of the major constraints to be addressed for the complete life cycle. This constraint has to be taken into consideration at the earliest possible point in a project and needs to be considered continuously throughout all phases of the design instead of being added afterward.

The CEAB evaluates all engineering programs to ensure that upon completion of their formal education, graduates engineers possess the required knowledge, skills and abilities to begin their career as a professional engineer. Accreditation criteria and procedures specify that engineering students must be made aware of the role and responsibilities of the professional engineer in society and must have appropriate exposure to ethics, equity, public and 
worker safety and health considerations, and concepts of sustainable development and environmental stewardship. While the accreditation board clearly indicated that safety and health must be included in all engineering programs, it does not stipulate how engineering programs should teach those contents to achieve the goal.

In order to provide students with the resources they need to become good design engineers, engineering programs should cover concepts, principles, and methods related to design for safety approach. The approach can be integrated in project-based design courses that integrate a real-world context for the development of design competency related specifically to safety. Engineering programs should also discuss standards, regulations, specifications and design handbooks that establish design minima. Those contents should be integrated throughout the curriculum of engineering sciences courses. For a while now, Dembe and Allard [3] have recommended the integration of health and safety into those courses. However, and in connection with safety, engineering science courses may go beyond the application of standards and guidelines.

Once again, the Case Study approach is a very good pedagogical strategy and can be used to explore the historical information available and to assess how integrating safety into the design process might have improved productivity, cost efficiency, and safety. This information is contained in the incident investigation reports completed after any incident causing worker injuries, illnesses or deaths. Those reports, published by the Workers' Compensation Health and Safety Boards, can normally be consulted on their WEB site and they describe the circumstances, the factual information, the analysis, the conclusions and a list of actions that should be undertaken to reduce the probability of the hazard that caused the incident. The incident reports contain reliable technical information based on the expertise of specialists. They often contain more information than needed to build a good case study.

The reading of investigation reports shows that many incidents could have been avoided if design for safety principles had been applied. Furthermore, the conclusions presented in the investigation reports point out changes and modifications that could improve workers' safety. The investigation reports gather very interesting pieces of information that can be used to develop very relevant case studies. Through such case studies, it becomes possible to link together safety, technical subjects and design. Because they are related to serious incident involving injuries and even deaths, such case studies have a strong educative capacity.
In our industries, there are too many serious incidents. Unfortunately, the potential for case study development is huge.

\subsection{Aim of the Paper}

The objective of this paper is to emphasize the viability of case studies based on incident investigation reports as a pedagogical strategy to expose students to safety and prepare them to integrate hazard analysis and risk assessments as an integral parts of the design process. To illustrate this idea, the paper presents an example of a case study used in a second year machine design course. The case is based on an incident involving three workers and a scissor lift. Two aspects of the case are described: the incident (circumstances, facts, analysis, conclusions and technical specifications of the lift) and the pedagogical scenario used with the students. Finally, this paper concludes with some strategic thinking related to the benefits that can be drawn from case studies built from incident reports.

\section{Example of a Case Study Based on an Incident}

The case study given as an example is based on an incident involving three workers and a scissor lift [2]. As shown in figure 1, a scissor lift is a type of platform that moves in the vertical plane only. The mechanism uses linked and folding supports in a crisscross ' $\mathrm{X}$ ' pattern. The upward motion is achieved by elongating the cross pattern. The incident report is published by the Commission de la sante et de la sécurité du travail and it can be downloaded from their WEB site [2]. The main points of the case study are summarized below to give a global idea of the case.

\subsection{Incident Circumstances}

There are many incidents causing serious injuries or deaths involving self-propelled elevating platforms. Four of them happened in the Province of Quebec alone during the 2003-2004 period [6]. In all occurrences, the platforms fell down because of defective or broken components, or other factors like a deficient or nonexistent maintenance program. In each incident, workers were seriously injured or died. To avoid such incident, the CSA B354.2-01 standard for self-propelled elevating work platforms [5] makes very clear recommendations for the maintenance and inspection of such equipment. In spite of that, accidents with platforms continue to happen. 
The incident of the case study happened on November 2003 at an aluminum smelter site located in the Côte-Nord region. Three workers were seriously injured, and one of them died after the scissor lift that they were using fell over and dragged them down.

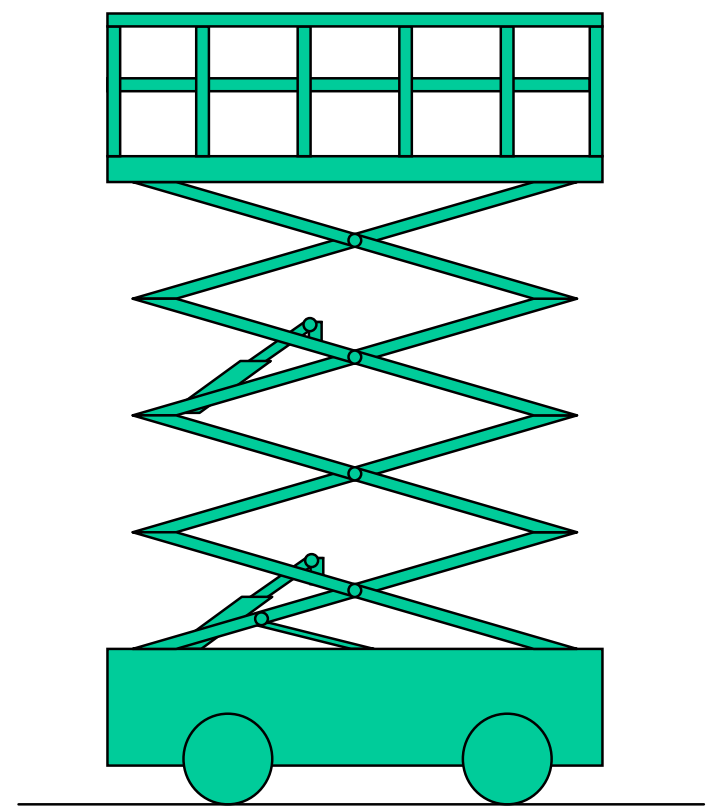

Figure 1. Scissor Lift

\subsection{Factual Information}

- At the beginning of the workday, the scissor lift was visually inspected by two of the three workers.

- After a few minutes of inspection, the three workers took place on the work platform and started their ascent.

While the lift was rising, at a height of approximately 11 meters $(37 \mathrm{ft})$, they heard the sound of a broken component. They stopped the lift, and after a short argument, they decided to go back down. After few meters on the way down, the scissor lift fell over.

\subsection{Conclusions of the Investigation}

The investigation agreed to the following causes:

- The central pin (pin \#1) of the lower scissor (left side) broke on the day of the incident.

․ The central pin (pin \#2) of the lower scissor (right side) was already broken on the day of the incident. a The rollers of the lower scissor legs fell out of their slides and caused the fall over.

- The inspection and maintenance of the lift were inadequate.

To prevent the incident, the workers should have been trained to use and inspect the scissor lift and a complete maintenance and inspection program complying with CAS B354.2-01 should have been adhered to. The corrosion and the broken pin were not detected; neither was the non-vertical axis of the unfolded platform (caused by the broken pin).

\subsection{Analysis}

The investigation showed that pin \#2, already broken on the day of the incident, was subjected to a slow torsion failure many weeks prior to the incident. The reason why the pin failed in torsion is directly related to the features of the joint design. The figure 2 illustrates the scissor articulation. As shown, one of the legs has two self-lubricating bushings separated by an aluminum spacer. The pins are nickel-plated in order to reduce friction. Because of the contact between different metals, the joint was subjected to corrosion under stress that inhibited the free rotation of the pin and scissor legs. The investigation also revealed that, in addition to the pin itself, the bolts of the pin cover were also broken. Because the bolted joint is weaker than the pin, it was concluded that the bolts broke before the pin.

Pin \#1 was overloaded because pin \#2 was broken. Analysis of the broken surface of pin \#1 indicates that bending was the predominant cause of the failure. The investigation revealed that pin \#1 was also subjected to corrosion. However, the day of the incident, rotation of pin \#1 was still possible but very stiff. A 7,000 lb load was needed to take out the pin from its bushing. Pin \#1 supported torsion, shear and bending. After a while, pin \#1 failed. When pin\#1 failed, the lower scissors disassembled.

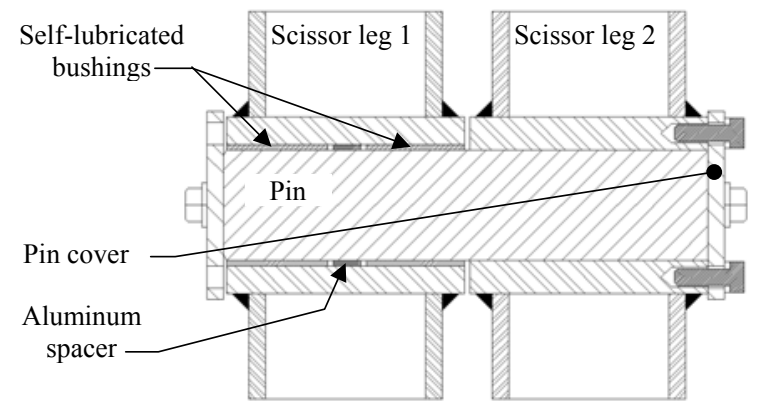

Figure 2. Design of Scissor Articulation 
The lower and upper scissor legs have roller skates that fit into a rail guide. There are eight roller skates, four for the upper scissors and two for the lower ones. Without the two lower pins, the lower roller skates fell out of the rail guide and the lift fell over.

\subsection{Technical Specifications of the Scissor Lift}

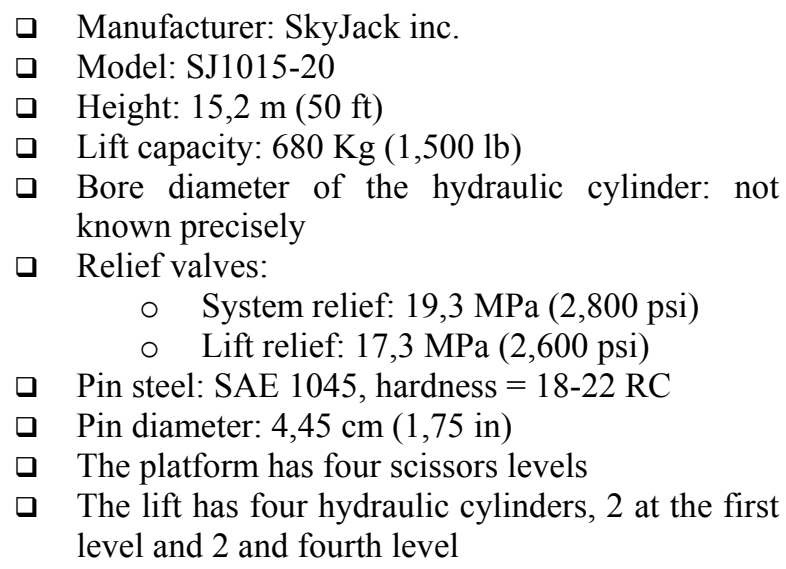

\subsection{Pedagogical Scenario}

The incident introduces many issues related to mechanical engineering matters. The two broken pins can be analyzed with failure theories to calculate the static and fatigue safety factors. Reaction at pinned joint has to be evaluated using static principles. The corrosion problem can be addressed in material science courses. Finally, the problem of maintenance is another matter that could deserve special attention.

Although case studies could have been developed for different courses, the Machine design course was chosen. Through lectures (4 hours total), the case was presented and the static problem was discussed. Among others, the relation between the pin reactions and the height of the lift was discussed. The challenge presented to the students was the calculation of the safety factors of the lower pins under three different conditions: 1) normal operation; 2) malfunction with one pin partially and completely seized by corrosion; 3) malfunction with one broken pin. To help them reach their target, a simple finite element beam model was made available and could be used to evaluate the stress components of the pin. In addition to the safety factor calculations, the students were asked to propose design improvements for decreasing the risk of hazard.

In order to "loop the loop", a 2-hour period was reserved for discussing design improvements and any other means that could help reduce the risk for the workers. During the discussion that concluded the case, good debates took place and gave the opportunity to emphasize the fact that when designing for safety, the order of precedence should be: a) to design for minimum risk; b) to incorporate safety devices; c) to provide warning devices; and d) to develop operating procedures and training. Finally, two questions directly related to the case were included in the mid term examination.

In addition to the application of engineering knowledge to a real problem, it emerges that the case study activities placed the students in situations where they could:

u understand the limits of the safety factor concept;

- establish the link between designer choices and the failure modes that can happen;

a appreciate the importance of a good maintenance program;

a understand the importance of taking immediate actions when malfunctioning or defective components are detected; and

$\square$ propose different design modifications for improving the safety of workers.

In addition to the above benefits, the case has certainly contributed to illustrate the fact that if a hazard is not avoided, eliminated or controlled, its potential may be realized, and a hazard-related incident may occur that has the potential to result in harm or damage, depending on exposure.

\section{Conclusion}

Because safety is of extreme importance, and that design engineers have certain responsibilities regarding safety, engineering programs have to ensure that graduate engineers have been appropriately exposed to safety and health issues. As CSA standard Z432-04 "Safeguarding of machinery" [4] proposes: the designer of a machine shall specify the limits of the machine; identify the hazards and assess the risks; remove hazard or limit the risks as much as possible; design guards and/or safety devices (safeguards) against any remaining risks; inform and warn the user about any residual risks; and consider any necessary additional precautions.

Case studies based on incident investigation report can favorably be used to expose students to safety and prepare them to integrate safety into the design process. The case example, presented in this paper and used in the machine design course, let the students apply their knowledge to a real problem and allowed them to consider health and safety issues. The case study clearly helped students to understand what hazard analysis and risk assessment mean. Based on the example, it is clear that incident reports are a good source for case study development. 


\section{References}

[1] CEAB: Canadian Engineering Accreditation Board, Accreditation criteria and procedures, 2007.

[2] CSST, Direction régionale de la Côte-Nord, Rapport d'enquête d'accident : accident mortel survenu à un travailleur et des blessures graves à deux autres travailleurs, le 6 novembre 2003 sur le chantier d'agrandissement de l'Aluminerie Alouette inc. à SeptÎles, EN-003494, Québec, 2004

[3] E. Dembe Allard, The Future of Safety and Health in Engineering Education, Journal of Engineering Education, avril 1996.

[4] CAN/CSA Z432-04 - Safeguarding of machinery

[5] CSA B354.2-01 (R2006), Self-Propelled Elevating Work Platforms.

[6] Métra, Angélique, Prudence avec les plateformes élévatrices automotrices!, Objectif prévention, Vol.. 29, NO 1, 2006

[7] Christensen, W.C. and Fred A. Manuele, Safety Through Design, ASME Press, 1999 